\title{
Sustainable Lifestyles: sites, practices and policy
}

\begin{abstract}
Pro-environmental behaviour change remains a high priority for many governments and agencies and there are now numerous programmes aimed at encouraging citizens to adopt sustainable forms of living. However, although programmes for addressing behaviour change in and around the home are well developed, there has been significantly less attention paid to activities beyond this site of practice. This is despite the environmental implications of consumption choices for leisure, tourism and work-related activities. Through focusing on sites of practice as a key framing device, this paper uses data from a series of in-depth interviews to identify three major challenges for academics and practitioners concerned with understanding and promoting more environmentallyresponsible behaviour. First, attention must shift beyond the home as a site of environmental practice to consider the ways in which individuals respond to exhortations towards 'greener' lifestyles in other high-consumption and carbon-intensive settings, Second, in broadening the scope of environmental practice, policy makers need to re-visit their reliance on segmentation models and related social marketing approaches. This is in the light of data that suggest those with strong environmental commitments in the home are often reluctant to engage in similar commitments in other sites of practice. Third, researchers and policy makers therefore need to move beyond the traditional 'siting' of environmental practice towards a spatially sophisticated conceptualisation that accounts for the multiple settings of consumption through mapping the relationships that exist between sites of practice.
\end{abstract}




\section{Introduction}

Encouraging pro-environmental behaviour has become a priority for numerous national and local governments as they seek to address a series of environmental challenges. Within the United Kingdom (UK), the Department of the Environment, Food and Rural Affairs (DEFRA, 2008, p. 3) has noted in its Framework for Environmental Behaviours that:

"The ultimate aim is to protect and improve the environment by increasing the contribution from individual and community action. This will come in particular from moving towards more sustainable patterns of consumption, covering the purchase, use and disposal of goods and services".

However, as documented by numerous academics, the factors framing and driving proenvironmental behaviour change are numerous as are the complexities of measuring and changing human behaviour (see for example; Eden, 1993; Burgess et al., 1998; Barr et al., 2001; Bulkeley and Gregson, 2009).

The expanding research agenda on consumer pro-environmental behaviour is characterised by a focus on specific practices related to issues such as waste management (Bulkeley and Gregson, 2009), water use (Shove, 2003), energy conservation (Barr et al., 2005) and a range of other 'green' consumer activities, including the purchase of organic foods and ethically traded goods (Seyfang, 2005). Indeed, within the setting of the household, there is a growing appreciation that environmental practice cannot be epistemologically separated from the everyday and thus embedded practices of consumption (Shove, 2003; Gregson et al., 2007; Verbeek and Mommass, 2008). As Bulkeley and Gregson (2009, p. 930) note when discussing waste management: 
"Such practices are deeply connected to issues of consumption, identity, value, and of maintaining social relations...; without their acknowledgement we risk missing the key processes through which waste is generated within and discarded by households, and their relation to questions of social ordering"

However, the connectedness of specific practices to consumption, identity, values and social relations has largely been framed within the 'home' as a particular site of everyday practice (Shove, 2003). Whilst the home can reveal rich understandings of the role of different social, economic and cultural contexts, there has been less research exploring the importance of differing sites of practice away from the home, along with their relevance to (differing) forms of environmental practice and the subsequent implications for policy formation. This paper argues that exploring different forms of environmental commitments in alternative sites of practice can demonstrate the (dis)connected nature of acting sustainably across a range of settings, which poses significant problems for policy makers attempting to encourage more sustainable lifestyles. The paper therefore argues that geographers and other social scientists need to adopt a broader conceptual approach through adopting an inter-disciplinary framework of analysis to understand and map the links between different, spatially diverse consumption settings.

These ideas are examined in three main ways. First, the notion of sustainable lifestyles is discussed through examining the various epistemological understandings of environmental practice that have developed to date semi-independently in the literature. Second, the notion of the sustainable lifestyle is explored with reference to both scholarly and policy-related literatures. This will emphasise the importance of linking theoretical 
work more closely to policy-facing literatures given the prominence of environmental behaviour in current policy discourses. Third, the paper discusses the role of differing sites of practice through examining the results of empirical research on sustainable behaviours. This explores sustainable lifestyles through the lens of both home-based and tourism-related practices covering a range of environmental activities.

\section{Environmental Practice: Disciplinary and Methodological agendas}

Research on what can broadly be termed 'environmental practice' spans disciplinary and, by definition, methodological agendas and it is therefore appropriate to provide a brief overview of how such agendas are constituted.

Conventional forms of framing and understanding environmental practice have been within, or closely aligned to, the quantitative psychological and sociological approaches that have become known collectively as 'environmental psychology' (Bechtel et al., 2002). Developing rapidly as a sub-discipline in North America, 'environmental behaviour' research has utilised both social psychological models (Fishbein and Ajzen, 1975; Ajzen, 1991; Schwartz, 1977) and psychological constructs such as the role of values, beliefs and norms (Stern et al., 1995; De Groot and Steg, 2008) to explore the pro-environmental behaviour. Indeed, these studies have also tended to focus on discrete practices and the factors that determine citizen participation, as the voluminous literature on recycling demonstrates (see Schultz et al., 1995).

Within geography during the 1990's, mounting critiques of such approaches (Burgess et al., 1998; Eden, 1993; 1996) led to a re-evaluation of both epistemological and methodological assumptions that underpin pro-environmental behaviour research as 
well as the attention policy makers were paying to the so-called 'deficit' model (Agyeman and Angus, 2003). The latter assumed that greater awareness and information would encourage public participation in sustainability issues. As Owens (2000, p. 1143) noted:

"...the "mental models" approach still suffers from too rationalistic a conception of agency and from a methodological individualism which abstracts human subjects from their social context".

Alongside this commentary on the deficit model, there was also a wider theoretical shift to critique the notion of environmental behaviour as a discrete and isolated form of social practice (Hobson, 2002). This focus on 'practices' was partly driven forward by Shove's (2003) new perspective within environmental sociology and more specifically the 'sociology of water' which has given rise to a renewed focus on the role of environmental practice within the everyday, the mundane and the 'normal' (Gregson et al., 2007). In so doing, an agenda has arisen around the 'social practices' approach in which, according to Verbeek and Mommass (2008, p. 634):

"Social practices are conceived as being routine-driven, everyday activities situated in time and space and shared by groups of people as part of their everyday life...Social practices form the historically shaped, concrete interaction points between, on the one hand actors, with their lifestyles and routines, and on the other hand, modes of provision with their infrastructures of rules and resources, including norms and values".

These intellectual agendas have, therefore, attempted to frame environmental practices through the lens of existing daily routines and habits within the home, thereby 
emphasising the importance of culturally-embedding the notion of environmental commitments within what is considered 'normality'.. As Owens (2000) notes, appreciating such social contexts is critical for understanding environmental practice, an issue that others have raised more recently (cf. Bulkeley and Gregson, 2009). Yet most studies in this field have been undertaken within and around the home environment and thus we still know very little about how practices are framed and performed outside of these particular domestic settings. However, recent research by geographers outside of the home environment has begun to demonstrate the importance of environmental practices at other sites of consumption. For example Tudor et al. (2008) have explored the role of environmental behaviour in the workplace, demonstrating the ways in which certain learned practices in work life are connected to those in the home environment whilst others appear to remain separate, thus raising questions about the complexity of relationships between these two sites of practice.

Indeed, sites of leisure and tourism hold another set of characteristics that can reveal the importance of exploring environmental practices in a very different consumption setting. As Chapman (2007) has demonstrated travel, leisure and tourism are crucial in terms of their environmental impact, and the rise of travel and tourism as an 'everyday' pre-occupation of the population (Urry, 2002; 2007) means that the touristic environment is also a critical site of practice for sustainability. An important issue therefore is the extent to which touristic sites of practice, imbued with particular expectations and meanings for individual behaviour, change the ways in which individuals as tourists perform environmental practices. In other words, has it become simpler for individuals to assimilate pro-environmental practices into their routines and 
habits in the course of daily, home-based consumption than in the setting of the tourism and travel environment?

This specific question relates to a much broader set of issues for environmental social scientists and geographers that lead us to question the wider conceptualisation of environmental practices that tends to be 'sited' in particular settings. A more fundamental issue to consider, therefore, is way in which practices map onto sites of consumption and the extent to which researchers and policy markers need to re-configure understandings of environmental commitments to consider space as a key issue.

\section{The Policy and Politics of 'Behaviour Change'}

The political imperative to engage citizens and promote behavioural changes has emerged as a powerful policy discourse in many developed nations (Lorenzoni et al., 2007). In the UK, despite several nationwide campaigns (Hinchliffe, 1996; Collins, 2004; Barr, 2008), the institutionalisation of behaviour change as a mainstream public policy objective was not embedded within policy until the publication of the third national sustainable development strategy in 2005 (DEFRA, 2005). Since then, DEFRA has invested considerable time and resources into developing its Framework for Environmental Behaviour (DEFRA, 2008). This outlines the strategic direction for UK behaviour change policy and a series of principles for encouraging UK citizens to adopt more sustainable lifestyles. In particular, these are framed by the notion that the urgency of climate change necessitates shifts in lifestyles and consumption practices amongst citizens.

The central component of DEFRA's strategy is the development and application of a segmentation model, in which seven types of individual are characterised according 
to a host of criteria, such as environmental attitudes, socio-demographic variables and the likely barriers and motivations for participating in environmental behaviour. These segments, based on the UK population, are mapped onto their propensity to undertake 12 key behaviours, themselves determined by their carbon impact DEFRA, 2008).

The emergence of this specific strategic direction has developed partly through the influence of another strand of research that lies at the interface between the academy and policy. As Darnton and Sharp (2006) have noted, academics and policy researchers have developed well in excess of twenty environmentally-based segmentation models to characterise the attitudinal and behavioural properties of individuals. In developing these models, authors such as Anable (2005), Barr and Gilg (2006) and Dallen (2007) have sought to argue that sustainable 'lifestyles' (in the sense of clear, attributable clusters of individuals) provide a useful means for targeting behaviour change policies according to established characteristics of the target group.

In developing this approach, DEFRA has advocated that by using segmentation as the basis for behaviour change, policy can be more effectively managed through social marketing strategies, which:

"... underscore the importance of strategically delivering programs so that they target specific segments of the public and overcome the barriers to this segment's engaging in the behavior" (McKenzie-Mohr, 2000, p. 594).

Accordingly, social marketing for sustainability has begun to emerge as a major policy and academic discourse (French et al., 2009) built on the developments that have occurred in anti-drug and anti-smoking campaigns that have focused on particular segments of the population. However, social marketing and the segmentation models on 
which such campaigns are based has recently been the focus of concerns raised by several social scientists (e.g. Peattie and Crane, 2005; Peattie and Peattie, 2009), who have argued that attempting to use marketing as a means to radically reduce consumption amongst the vast majority of the population is likely to have only limited impact given the embedded nature of consumer practices and their implicit relationship to the importance of economic growth in contemporary society. However, an outstanding issue with this approach is the specific role of differing sites of practice. In DEFRA's (2008) segmentation model, for example, the majority of behaviours were related to home-based practices, rather than those employed in a work or leisure environment. As with our discussion of the ways in which research on practices has developed through a focus on domestic settings, policy approaches have also been dominated by models of change that are grounded in notions of sustainable lifestyles based on practices performed largely in and around the home. This raises questions over the ways in which policy markers define the spatial boundaries of their influence and the extent to which notions of sustainable lifestyles can and should extend to other settings, within which there will be different and potentially competing policy influences. Accordingly, building on both the intellectual and policy challenges posed by exploring environmental practices beyond the home setting, the remainder of this paper will explore the role of touristic sites of practice in framing environmental commitments as a way of illustrating the broader ways in which different spaces of consumption need to be considered for policy-related research and practice focused on behavioural change. 


\section{Sustainable Lifestyles: Exploring Alternative Sites of Practice}

In this paper we argue that research needs to focus on different sites of practice as a way of understanding and questioning 'sustainable lifestyles'. In so doing we wish to look beyond individual settings, towards a framing of environmental practice that incorporates the geographical siting of consumption and the relationships that may exist between these sites. In advancing this argument it is important to recognise the complexity of social practices and their relationship with different sites. For example, notions of the 'everyday', 'mundane' and 'normal' (Shove, 2003) have become as much part of touristic experiences as exceptional and 'special' events have entered the home environment (Urry, 2002; Hall, 2005). Accordingly, we do not seek to definitively associate the home with 'everyday' (or normalised) practice and tourism with 'exceptional' experiences; rather, we aim to explore the relationships between home-based and touristic practices. For example, Krippendorf's (1987) seminal research in this field observed that tourists brought with them many of the practices of home life into the holiday setting and that these tended to be important for those tourists for whom familiarity of routine was important (Gottlieb 1982). In contrast, Currie (1997) identified a range of 'behaviour reversals' or inversions between practices at home and whilst on holiday (Shaw and Williams 2004). Whilst these studies do not encompass aspects of pro-environmental behaviour, they nevertheless raise the possibility that 'normalised' sustainable practices in the home may sit alongside equally 'normalised' but unsustainable behaviours in sites of leisure and tourism.

This paper reports on part of a research project examining aspects of sustainable holidays, environmental behaviour and climate change. The broader project sought to 
explore how sustainable lifestyles were framed in spaces of leisure and tourism, and it also examined the role of low-cost airline development in public discourses on air travel and climate change. In order to meet the academic and policy-related goals of the research, a segmentation approach similar to that applied by DEFRA was adopted, thus making the results partly comparable and enabling the authors to provide an appraisal of this approach through the subsequent analyses during the second and third stages of the research. Accordingly, the research strategy involved three stages. First, a convenience sample of 202 individuals was asked to complete a short questionnaire in central Exeter, UK, during April 2008. The questionnaire asked a series of closed questions regarding pro-environmental behaviour in the home setting (recycling waste, energy conservation, water saving, 'green' consumption) alongside similar questions for sites of leisure and tourism. The survey also comprised a series of attitudinal and demographic questions. On the basis of the behavioural data, the sample was subjected to hierarchical cluster analysis using SPSS 14.0 (Wheeler et al., 2004) and three major groups were identified on the basis of their reported environmental practices. Using these segments as a sampling frame, stage two of the research involved asking individuals representative of each cluster to attend focus group discussions where their responses were probed in greater detail. Finally, the third stage of the project involved twelve in-depth interviews with members of the sample. These interviews were designed specifically to discuss sites of practice in relation to environmental commitments and it is these discussions that form the basis of this paper. Accordingly, each interviewee had nominally been assigned to one of the three clusters identified by the quantitative analysis. Whilst not the focus of this paper, but by way of contextualisation, the three clusters are briefly described in Table 1 as an aid to 
the following qualitative analyses. The final row of the table provides the names of the interviewees whose discourses are used in the following analyses and the cluster to which they nominally belonged.

The broad constitution of the clusters related to reported environmental commitments both in the home and whilst on holiday. The first cluster may be considered the most environmentally 'committed' and contained individuals who participated in a wide range of environmental activities both at home and whilst on holiday; members of this cluster also tended to fly the most frequently and to more distant destinations. The second cluster also contained individuals who engaged in numerous environmental practices in the home, but rarely carried these across into leisure settings. In the third cluster, members tended to engage in fewer environmental practices, but carried these practices across on to their trips. In addition to these data, Table 1 also provides specific information regarding each cluster's attitude towards carbon offsetting schemes and related taxation measures.

[Insert Table 1 here]

The analysis of these data is presented in three main parts in an attempt to illustrate the role of sites of practice through examining three settings: 'the home', 'the holiday and 'the journey'. In so doing, the analysis will illustrate the (dis)junctures that occur between these three critical sites of practice for sustainability. As with all social research that utilises interviews as a data collection tool, the focus here is on discerning discourses that emerge through conversation and there are clear limitations in making a direct link to actual observable 'behaviour'. Rather, this research, like other work that has examined social practices (Shove and Warde, 2002), aimed to explore with individuals 
their own social realities in ways that are meaningful to them, thus overcoming some of the problems associated with the 'measurement' of arbitrarily defined practices sometimes used in quantitative research. However, as a prelude to these data and as a way of contextualising and introducing the interviewees, the respondents' views on environmental issues, and specifically climate change, will first be examined.

\section{Acting in an 'Environmentally-Friendly Way'}

To generate conversation at the start of each interview, respondents were asked what it meant to act in an environmentally-friendly way and, subsequently, whether they felt any responsibility personally for global climate change. In response to the first question, the responses were relatively consistent:

"Well to preserve the environment as much as possible, not waste things and use whatever resources we've got at our disposal as economically as possible" (Martin, Cluster 2)

“...like recycling and not using too much energy and not using so much water and just that kind of thing really" (Jean, Cluster 1)

The emphases in these responses were placed on 'saving' things and reducing waste, both of which have become common themes in the geographies of sustainable lifestyles (Gregson et al., 2007). Furthermore, the responses were invariably related to the everyday practices of the individuals concerned and were illustrated by numerous examples, all of which framed environmental action as a personalised, individualistic commitment. Thus within this narrow setting, it is notable that none of the respondents mentioned climate change as something that imbues environmental practice with 
meaning. With the exception of one case, climate change as an issue was viewed with either scepticism or at least as only having supplementary importance when viewed within the context of wider environmental issues. Moreover, this was before the widelypublicised controversy concerning the reliability of some climate data utilised by the Intergovernmental Panel on Climate Change (IPCC) in late 2009 and early 2010 (Heffernan, 2010).

As Lorenzoni et al. (2007) have noted, various public discourses surround climate change and our discussions with the interviewees revealed three dominant themes. First, both Dan and Donna highlighted their scepticism concerning climate change. In both cases, the natural cycle of climate changes is used to argue that humans are not or are incapable of effecting climatic alterations:

"I don't actually believe that mankind is actually making a lot of difference. The Earth is purely a natural...process" (Dan, Cluster 3)

"I think it's a natural part of the World's cycle" (Donna, Cluster 2)

A second discourse related to scale and the relationships between individuals and other states or organisations as key actants. This was framed as an issue of response efficacy or more broadly as a lack of empowerment. Indeed, it stresses the individualistic notion of environmental action taken to its extreme:

"I do [feel concerned about climate change] but the world always changes anyway...a little person like me can't stop the Americans driving their cars...so I can’t worry about it” (Gemma)

Third, some individuals expressed concerns and used illustrations of previous or current events to emphasise their points. Such comments exemplify the contested 
knowledges that surround climate change and the coalescence of different global events under one, all encompassing label. Indeed, many interviewees noted the media coverage of climate change and the disagreements between professionals concerning both its reality and provenance:

"I do worry about climate change... especially when you look at Burma and the [2006] Tsunami and even...the earthquake in China” (Anna, Cluster 1)

"Well I do worry a little bit about it...you'll get one person saying air travel contributes $6 \%$ to emissions and there'll be somebody else saying it's $20 \%$ and because of that lack of understanding it looks stupid" (John, Cluster 3)

These discourses reveal that, whilst environmental behaviour has become an accepted and established principle for most individuals, this is largely based on essential qualities - saving, not wasting; being mindful to use resources carefully - rather than a pressing and clear agenda related to climate change. However, although providing a background for the interviewees and their environmental discourses, the discussion has so far been somewhat unrelated to the wider settings of environmental practice. Accordingly, the following three sections will explore how these individuals frame environmental action at different sites of practice: within the home, on holiday and for 'the journey'.

\section{The Home}

In using sites of practice as a framing device, 'the home' has received the vast majority of attention when viewed as a site for sustainability (Bulkeley and Gregson, 2009; Davies, 2008). Conventionally, researchers have focused on specific behaviours, such as 
recycling waste, saving water, conserving energy and so on. However, rather than focusing on these specific practices, our interviewees were asked to describe their environmental practices in the home as a way of teasing out discourses on the site of practice. Not surprisingly, respondents began with a commonly used example:

"Well we recycle as much as we can. We've got the old green and grey bins so we use that as much as we can, in fact there is very little that goes into the grey, so I think we do all that we can in that direction and of course we've got the recycling in the garden as well" (Martin, Cluster 2)

For all interviewees, recycling had become an established practice within the home, facilitated by the provision of services and receptacles that had normalised and materialised environmental practice. However, for many individuals the following quotation provides an indicative illustration of their responses:

"I mean for instance I take the train to work rather than do the park and ride because I don't see the point in using my car and that works, that's really convenient, that's easier than driving really. So there's no problem there. When it comes to recycling, that's easy because we happen to live within a very proactive sort of council locality, so that's good. Food miles is something that I am always very aware of but never quite manage to, sort of, balance it out all of the time just because I think it's hard really when you are trying to cook for a family and you're on a budget as well. I try and, sort of, make sure the vegetables that I buy aren't flown over and I always try and buy British and I've got an allotment which is very unsuccessful at the moment so I try and grow my own fruit and veg, so I am very aware of that" (Anna, Cluster 1) 
In this instance, Anna weaves a question of environmental practice into an answer about her everyday consumption practices, highlighting the ways in which certain forms of environmental behaviour have become part of her consciousness. Indeed there was little contestation of the home as a suitable site within which to practice sustainability. Even among those who were less inclined to participate in activities labelled as 'environmental' there was no hostility towards activities like recycling, energy saving or more sustainable forms of consumption. Rather, individuals reflected on why they engaged in certain practices and not others, invoking the notion of 'habit':

"The biggest difficulty I think is one of habit, as in your changing habit of a lifetime, and that, whilst rationally you should be more environmentally conscious and dispose of waste in the right way, actually you don't. You just find the easiest option so you... always tend to go with the easiest option" (Dan, Cluster 3)

The discussion of home-based practices was therefore one based on a largely 'unspoken' acceptance that so-called pro-environmental activities were the norm for many individuals. There were few activities which were regarded as unacceptable in the home and many had become embedded, unquestioned and largely unnoticed everyday routines. Indeed, as the discourses on climate change indicate, these habitual practices are only likely to have been influenced indirectly, if at all, by the emerging debates on global warming. Rather, the discourses revealed here amongst individuals representative of the different clusters indicate 'common sense' environmentalism, one that is related to deeper notions of being frugal and treating resources with care and of course, saving money: “...it's the way you're brought up, you switch things off and sort of try and economise because you still have to pay for it in the end" (Gemma, Cluster 3) 
Yet whilst this 'common sense' environmentalism was widely practised in the home and mostly accepted, the assumptions underlying environmental practice beyond the home were markedly different, both in terms of perception and commitment.

\section{The Holiday}

The notion of 'sustainable tourism' from the perspective of individual tourists has been extensively researched in recent years (Mowforth and Munt, 2003) and has largely focused on resort-based studies of tourist impact and perception (Sharpley, 2009). However, there is an emerging intellectual agenda, which is dealing specifically with climate change and tourism (Becken and Hay, 2007; Gössling and Hall, 2006). This has begun to grapple with the issues of travel and transport (Anable, 2005; Dallen, 2007; Sharpley, 2006) and tourism's impact on the climate (Gössling and Peeters, 2007; Scott et al., 2010). Related in style to the social psychological research undertaken within the home setting, this research has revealed a set of barriers and motivations for participation in various sustainable tourism initiatives, from saving water and energy to green and ethical consumption practices whilst on holiday. However, as Dickinson and Dickinson (2006) note, these studies have rarely explored notions of sustainable tourism within a broader framework considering sites of practice and the ways in which 'sustainable' tourists practice sustainability in other settings.

Interviewees were therefore asked to talk about what sustainability meant to them when they were on holiday and whether they engaged in sustainable practices whilst in these leisure environments. Within these discussions, a range of discourses emerged that 
later revealed differences between the interviewees in how they framed environmental practice on holiday. For Janet (Cluster 1):

"It wouldn't stop, I would always still turn the taps off and have showers instead of baths and that sort of thing"

A number of interviewees mentioned water saving as an activity that they continued when on holiday alongside another habitual activity - energy conservation. Indeed, typical responses to this question were that "it's just the same" or "I don't really think about it". However, on probing more deeply into specific practices, it was evident that, as might be expected, holidays yielded different patterns of consumption:

“...sometimes you use convenience things... I suppose if I had a small baby I would use disposable nappies whilst I was abroad. I wouldn't do that if I was at home. I certainly didn't when I had small children. I always used proper nappies so therefore that would be one example I can think of. I suppose the other thing is that certainly when you go abroad like small things, you use a face cloth or a flannel here and wash it out, that's not quite so easy when you're abroad and people use more disposable tissues and that kind of thing" (Pat, Cluster 1)

Indeed, there was also evidence that for some individuals, their efforts to engage in environmentally conscious practices in one domain may contradict their behaviour at home:

“....and to save us washing over there we've bought some special stuff to hand wash. That's okay with using our own water and we're taking paper bibs so that we don't have to wash loads of bibs over there and you know things [that] we can throw away" (Jane, Cluster 1) 
The 'waste' issue raised by Jane was an important discourse during the interviews and reflected the 'the holiday' as a site of practice. For most interviewees, the perceived lack of recycling services (or functional knowledge of these) was highlighted as a major problem and once again illustrated the conflicts that emerged between the home and holiday settings:

"My behaviour would only change if there were different facilities available or if I had needs, I guess...but if I can't recycle things then I won't; I might throw more things away because...you can't reuse them if you are travelling so it does change but not my feelings towards it" (Janet, Cluster 1)

What these individuals highlighted, therefore, was an awareness of sustainability issues in a leisure setting; they were able to frame and discuss environmental sustainability across both the sites of 'the home' and 'the holiday'. For most, habitual actions such as saving energy or water continued. Indeed, there were aspirations to do more, but these were often mediated by the different patterns of consumption that characterise holidays and the varying ways in which the outputs from this consumption could be managed. There was also evidence that individuals recognised some contradictions in the ways that they attempted to adapt to these new sites of practice: for example, was it better to save water by not washing nappies and bibs, and to use disposable ones instead? These conflicts were mostly minor, but become far greater when the impact of 'the journey' is considered.

The emphasis on sites of practice was, however, far greater for other individuals for whom the holiday was not a continuation of their 'sustainable' lifestyles at home, but 
rather a break from 'being good'. For Gemma (Cluster 3), thinking about the environment when on holiday was not a priority:

"I don't think it would come into it. I think, 'I don't want to be bothered with sorting rubbish out'; I think, 'You're on holiday, you are there to relax and enjoy yourself' and you really don't want to be thinking what bin does this go in. You just want to get rid of it...It's precious, your holiday, and all the year saving up for it, you don't want to be wasting time on rubbish really".

Accordingly, a holiday was a distinct change for a short, but significant period of time. This time was special, reserved and definitely not part of the everyday. As Donna (Cluster 2) remarked:

"I have to say if I'm on holiday and I would have to seriously go out of my way...to do something environmentally friendly. I wouldn't because if I'm paying to go away and relax, that's what I'm going to do, at the cost of the environment or not".

These remarks have two important implications. First, they imply that as apparently 'special' sites of practice, holidays often become places of difference where individuals can engage in 'dreamed' (Urry, 2002) forms of consumption that can only be maintained for a short time. In these settings, “...you just go on holiday to enjoy yourself and you just forget about everything" (John, Cluster 3). This difference is also expressed in the breaking of habits, routines and practices for sustainability that mark out and codify the home environment. Such a marking out of sustainability 'territory' is significant, because it raises significant challenges for those who seek to advocate major changes in people's 'lifestyles' across sites of practice. 
However, a second implication is that the potential binary formed between the home and the holiday is testimony to the progress that has been made in and around the home. For most of the interviewees, there was a lucid and fluid discourse on their sustainability practices in the home and, as Gregson et al. (2007) have indicated, these behaviours relate strongly to everyday forms of consumption and the movement of materials and goods within the household. A holiday -that is, by definition a 'different' experience and setting- challenges many of these established practices and thus creates a potentially new and important site of practice for (un)sustainability.

\section{The Journey}

A final site of practice is what we have broadly termed 'the journey', a reference to the transition between the home and the holiday, a transient and yet critical space for performing sustainability. As noted in the introduction to this paper, the popular attention given to the issue of air travel and climate change in recent years in the United Kingdom has represented a series of conflicting discourses surrounding the role of flying and its impact on climate change. Indeed, the rise in low cost carriers has meant that air travel continues to grow rapidly and has enabled wider access to cheap, regular short-haul air travel (Graham and Shaw, 2008).

Within the tourism literature, air travel's impact on climate change has been explored technically (Gössling et al., 2006) but also critically with reference to tourist perceptions of climate change. As noted by Gössling and Peeters (2007), the debate surrounding flying and climate change represents a contested and highly emotive issue that relates back to broader issues in climate change understandings (Lorenzoni, et al., 
2007) explored earlier in this paper. However, there are also clear indications that flying, just as with holidays, represents a specific setting and thus generates a further set of discourses related to sustainability and mobility (Becken, 2007; Ryley and Davison, 2008; Urry, 2007).

When interviewees were asked about their flying habits and how they felt these may impact on the environment, a similar discursive division between the respondents emerged to that which characterised environmental practices whilst on holiday. The first discourse related to flying as a necessary activity, but one for which individuals ought to feel 'guilt' (for individuals representative of Cluster 1, Table 1). The second was oriented towards an equivocal position where respondents, aware of the media coverage of flying and climate change, emphasised the benefits of low-cost flights and the controversial evidence surrounding flying's impact on the environment (for individuals representative of Clusters 2 and 3).

For those who saw flying as a necessary 'vice', certain characteristics emerged from the interviews that matched the quantitative data (Cluster 1 in Table 1). These individuals tended to fly frequently for leisure and also tended to visit international destinations (those mentioned included Nepal, Australia, Thailand, Cambodia, New Zealand and the Caribbean). These flying habits are important not only for the carbon emissions that are a by-product of such flights, but also because these individuals tended to have been less affected than others by the boom in low-cost air travel.

As noted, these individuals also tended to be those who were very committed to environmental practices both at home and on holiday. This apparent contradiction was 
highlighted by a number of interviewees without any prompting. Anna (Cluster 1) provides a good illustration:

"Well going, flying out there you are immediately cancelling out your environmentally-friendly attitudes because you are doing something that isn't environmentally-friendly, so it is hard, isn't it? I suppose I, yeah, I suppose really I don't pay as much attention to the things I would do at home to make my everyday life, a more environmentally friendly one but the issues are there".

For these individuals, air travel had become part of a leisure culture that was unquestioned and manifested in holiday practices; to go on holiday was to fly. Yet these were also people who defined their home lifestyles through vigorous environmental commitments. Jean (Cluster 1), for example, had recently attended a programme run by the environmental charity, Global Action Plan, that seeks to promote sustainable living:

“...it was only when I did do the Global Action [Plan] and Small Change project that it made me think about it..., because I've been to New York I felt very guilty about that because it was on there, one of the causes".

In recognising some of the potential contradictions, other individuals discussed mitigation or compensation strategies that would partly assuage their anxieties about flying and climate change. Jane highlighted the following approach:

"Yeah, well we're not too happy [about flying to the Caribbean] because like my children have told me all about flying and it's bad for the environment and everything like that but I mean we're, rather than going out and buying bottled water, which is quite expensive anyway; we've bought a water purifier which we're taking with us, which was more expensive but we've bought it so that we're 
going to use their water and purify it ourselves. So we won't have all these big plastic bottles to dispose of over there" (Jane, Cluster 1).

These strategies of mitigation reflect ways of reconciling an apparent acceptance that air travel is problematic with established ways of being environmentally conscious cutting down waste or using local public transport. However, there is also a tangible sense that flying and climate change are highly challenging as environmental issues because of the symbolic value associated with air travel and tourism. Accordingly, the emergence in some parts of the popular media of air travel as a destructive and potent anti-environmental discourse has therefore presented travel and tourism as a potential site of conflict.

The challenges posed to those most committed to the environment within the setting of 'the journey' are not reflected for those who were less inclined to be environmentally conscious on holiday. A major theme to emerge was similar to that expressed regarding holidays:

"I am now in a financial position to be able to go on holiday more than I was, say, 10 years ago so because I can afford it. I do go on holiday more. I don't worry about the environment where flights are concerned, remotely. I'm not a good flyer but flying is the quickest way to get from A to B and if you want to see the world that's the way to go" (Donna, Cluster 2)).

For interviewees like Donna, flying was not related to the environment; or rather flying was not a suitable setting for considering the environment. This is closely related to previously-discussed understandings of climate change science and risk (Lorenzoni et al., 2007) and a number of interviewees were confident and ebullient in dismissing claims 
concerning carbon emissions, air travel and climate change. As Donna (Cluster 2) continues:

"I mean, I've seen An Inconvenient Truth. I think I took that with a pinch of salt. I can see that the fuel burnt is not such a good thing as indeed with deodorants and such like. I remember all those years ago that hairsprays and underarm deodorants were such a bad thing and so they changed the CFC's or whatever they were but my personal view is the world is evolving, it adapts remarkably well, mother nature is an amazing thing and...we will either have another apocalypse, ice age or meteor strike and we'll start a fresh, or mother nature will just sort us out and rebalance the world so no".

These interpretations of climate change and air travel are significant because they point to widely-held views from the preceding focus groups that indicate a mismatch between stated concern about global climate change and the understandings and interpretations individuals place on specific causes and solutions. Frequent questions were raised by interviewees regarding technical questions, such as:

"How much fuel does the train use between London and Edinburgh? And how much carbon emissions does it put out?... I could imagine it's equally as bad [as air travel] if not worse" (Martin, Cluster 2).

However, as potent as these discussions were, an equally powerful discourse emerged regarding the benefits of flying, particularly the emergence of low-cost carriers in providing the ability for people to travel more frequently, at their convenience and for lower prices: 
“Low cost carriers; I think they’ve changed the way people think about air travel; they've had a huge impact" (John, Cluster 3).

For Martin (Cluster 2), the benefits of being able to fly from a local airport to numerous destinations were also significant:

"One big holiday here and America in September, like a long holiday, and then we've got our regular week in Madera that we normally go to and we do travel as well because my daughters live quite far away. I mean, one daughter lives on the Isles of Scilly so we're always flying over to Scilly and so yes we do more holidays"

Accordingly, for individuals like Donna, John and Martin, air travel, particularly low-cost carriers, has enabled them to fly more frequently and at lower cost. For these individuals, flying is therefore characterised much more by a major re-orientation in their leisure horizons that low fares airlines have afforded them, critically at a lower cost. As John noted: "...the law of economics is far more important to us than the law on environmental science". Indeed, the perceived inconsistencies in information and knowledge surrounding climate change were mobilised to create a clear distinction between the home, where environmental practice was normalised and routinised, and the 'the journey', where (like the holiday) emphasis was placed on its special characteristics something that was untouchable and critical to maintaining a desired lifestyle. As John (Cluster 3) noted:

“...people will fly whether you like it or not and you can't change that now, you can't put the genie back in the bottle". 


\section{Discussion}

By framing environmental practice through the lenses of 'the home', 'the holiday' and 'the journey', this paper has sought to illustrate the importance of sites of practice in shaping both discourses and actions. The analysis largely supports the assumptions underlying the social practices perspective in environmental social science (Verbeek and Mommass, 2008), in which the everyday and the mundane have become the focus of research in and around the home (Hobson, 2002). Evidence from this research illustrates how, for specific behaviours, there is a largely indistinguishable relationship between daily practices in the home and what are commonly termed 'environmental practices'. However, the focus of this paper has been to advocate a move beyond the domestic setting to an exploration of the ways in which environmental practice is framed and mediated by alternative sites of practice, as well as the extent to which normalised forms of behaviour may come into conflict with strongly held environmental beliefs when performed in different settings. Thus, we would suggest that the evidence presented here indicates a need to re-frame scholarship and policy making so that sites of practice, of consumption, also become critical to the analysis of environmental behaviour.

\section{Siting Practice}

A re-focusing of the research agenda in this manner would suggest that the process of moving beyond the home is both disruptive and challenging for those who have embedded sustainability into their daily practices. Accordingly, in our analysis, we concur with the findings of Dickinson and Dickinson (2006) and Hunter and Shaw (2007) who have called for a more geographically-sophisticated approach to studying 
environmental behaviour. This is urgently needed in order to map the relationships between different sites of practice that are attaining greater importance with increasing levels of personal mobility.

The analysis of the interviews in this paper indicates that, whilst being 'environmentally-friendly' is a well-defined and uncontested discourse within the home, divergent discourses emerge when holidays are discussed. For some, holidays represent discrete sites of practice - places to relax, play, enjoy and above all to adopt the 'normality' of holiday taking. For these individuals, their (embedded) sustainability practices in the home are treated unquestioningly alongside other established behaviours, which are in turn regarded as inappropriate within a tourism and leisure setting. This clearly relates to Currie's (1997) notion of 'inverted' behaviour and is now a common theme in tourism studies (Shaw and Williams 2004) that suggests different forms of 'normalised' practice emerge between the home and tourism settings.

However, a further discourse relates to a tension that emerges for others who seek to transfer both the ideas and materialities of their 'sustainable lifestyles' into the holiday setting. This is not to suggest that these individuals hold fundamentally different motivations for their leisure time than others, but rather that they place greater emphasis on environmental practice as everyday practice (be that at home or on holiday) in identity formation and social interaction. For these individuals, there is a constant and nagging questioning of practice, which can result in compromise and frustration as they seek to reconcile the ethics of environmental sustainability with the established practices of holiday taking. 
These emergent discourses for 'the holiday' are, however, brought into sharper contrast when 'the journey' is examined. The high-profile media coverage of air travel and climate change in recent years has resulted in heated debates concerning the impact of flying on global carbon emissions and the role of individuals to abstain from flying or to offset their carbon emissions (Chapman, 2007). Within the interviews, divergent discourses once again emerged. However, these discourses were framed in starker environmental terms and for some this evoked arguments concerning climate change science, air travel's impact on the climate along with practical concerns a cost and convenience. For others, air travel was an accepted 'bad' - something, which they recognised as being negative, but necessary within the context of their broader lifestyles. Accordingly, for many 'the journey' represented a critical axis point around which their consumption practices revolved - between the home and the holiday - and for both groups of individuals, there was little appetite to reduce this activity.

These discourses illustrate the need for researchers to explore alternative sites of practice as critical framing devices beyond the confines of daily, home-based social, economic and cultural settings because of the ways in which they are imbued with their own ascriptions of value, meaning, consumption and identity. Navigating sites from the 'home' to the 'touristic' can thus be disruptive and can lead many to assert that an appropriate setting for 'environmental' action is not the holiday or the journey, which are themselves sites of practice that hold different values as spaces of consumption.

Such conclusions inevitably pose a major challenge for policy makers concerned to reduce carbon emissions through exhorting individuals to use alternative modes of travel for leisure and tourism journeys. The findings of this research indicate that just as 
certain pro-environmental practices have become embedded in the everyday life experiences of households, the 'everyday' experience of tourism also embeds negative environmental behaviours. For some, these two 'normalities' can co-exist comfortably; for others, there is a recognition of this tension, albeit an acceptance that the consumptive value of normalised touristic practices is too powerful to challenge.

\section{Climate Change and Environmental Practice}

The discourses emerging from the interviews on environmental practice illustrated the divergent ways in which the notion of acting to tackle climate change was framed by respondents. Indeed, these discussions were mediated by their setting; individuals rarely raised questions or objections about undertaking environmental actions in the home; this was after all established practice and was part of daily routine and habit. Yet there were varying and divergent perspectives on climate change - whether it was happening, if it was, who was to blame and who had to act. It was clear that the actions which individuals framed as environmental behaviour were largely concerned with other environmental issues or non-environmental issues. 'Saving and not wasting' was therefore imbued with multiple meanings and implications, yet climate change did not feature as one of these.

This suggests that climate change is, for all intents and purposes, a relatively minor issue when it comes to embedding environmental practice, particularly in the home setting. Indeed, when climate change did emerge as a theme, it did so as a contested subject, often concerned with practises related to holidays and particularly air travel,. Many of the discourses that were displayed relate to findings from both Lorenzoni et al.'s (2007) research on UK attitudes towards climate change and the specific research of 
Gössling and Peeters (2007) on tourism and air travel. These indicate that many individuals are unclear concerning the definition of climate change and its effects (including tsunamis and earthquakes), the likelihood that climatic change is occurring, the role of individuals in that process and the responsibility of other state and non-state actors in tacking any problem. Accordingly, as Giddens (2009) has argued, climate change, far from being at the centre of a concerted and vigorous effort to engage in environmental practice, largely remains a contested albeit over-bearing issue for many citizens.

\section{Lifestyles, Sites and Policy}

A final theme to emerge from this paper relates to the broader issue of 'sustainable lifestyles', a broadly applied and ill-defined term (Hobson, 2002) that has been used both to describe (Jackson, 2005) and analyse (Barr and Gilg, 2006) pro-environmental commitments, thus enabling researchers to derive 'lifestyle groups' on the basis of certain characteristics. The interview data indicate that, on one level, this concept is highly problematic as a classificatory tool; the three quantitatively defined groups in this research were segmented on the basis of their home-based pro-environmental behaviours and it is clear from both Table 1 and the interview transcripts that it is not possible to ascribe any one group to being consistently sustainable or unsustainable. The groups are clearly defined, in part, by social context and must be interpreted accordingly. However, an exploration of the ways in which individuals between the groups discussed different sites of practice clearly displayed certain similarities with regard to their framing of sustainability in a holiday or travel setting and researchers need to examine how 
conventional notions of exploring 'lifestyle' groups can be developed to plot the morphology of practices across different sites.

More broadly, the research in this paper suggests that the 'policy problem' of sustainable lifestyles needs further analysis, especially given the British Government's (DEFRA, 2008) recent focus on using segmentation and related social marketing approaches to understand and promote behaviour change. Our results suggest that, whilst there may be some merit in using the home as a site of practice for framing sustainable lifestyles, the logic of extending assumptions about environmental practice into sites of leisure and tourism is important yet problematic. This is not least because, as Peattie and Peattie (2009) have noted, the ideas of segmentation and social marketing becomes increasingly challenged when techniques grounded in marketing theory are applied to efforts to reduce consumption.

\section{Conclusion}

This paper has sought to illustrate the role and importance of 'siting' environmental practices as a way of understanding how environmental commitments are mediated by different, spatially configured settings. In so doing, we have not only illustrated the ways in which 'environmental behaviour' is codified at different sites of practice by wider issues of consumption and identity, but also where research and policy now needs to focus. We conclude by outlining three major challenges for researchers and policy makers seeking to understand and promote environmentally sustainable practices.

First, geographers and other environmental social scientists need to focus on the role sites play as key framing devices for environmental practices not only to further our 
knowledge on the relationships between particular settings for consumption but also to challenge existing notions of sustainable lifestyles, which require spatial configuration. We therefore argue that both researchers and policy makers need to make room for space as a key device for framing and critiquing sustainable lifestyles and that geographers in particular need to consider a new spatiality of environmental practice that develops an analytical sophistication for multiple consumption settings.

Second, in regard to global climate change, the scientific and economic evidence (Chapman, 2007) indicates that air travel and tourism's wider impact on the climate is likely to increase exponentially as the number of flights increases, both in the developed but critically the developing world. However, the evidence in this paper suggests that despite these scientific challenges, there is little to indicate that even those with the greatest environmental commitments in the home are likely to reduce flying in the near future because of concerns over climate change. Indeed, the paper indicates that climate change is far less of a critical issue for individuals than might be considered popular opinion. Accordingly, environmental social scientists need to understand in much more detail the ways in which climate change is related to ideas of practice and how discourses on climate change may differ between alternative settings.

Third, the data we have reported on issues such as climate change and environmental practices in touristic settings present a major challenge for policy. From the perspective of DEFRA (2008), who have emphasised the carbon-focused nature of their recent Framework for Environmental Behaviours, whilst home-based practices are largely accepted as everyday normal behaviours by a large number of individuals, promoting travel or tourism-related behaviours may be very challenging given the 
apparent lack of resonance many individuals have with climate change issues. Indeed, the utilisation of segmentation models and the subsequent use of social marketing strategies as the basis for behaviour change are only likely to be effective when these are developed across different sites of practice and thus account for the differing ways that individuals frame environmental practice.

The challenges for academics and policy makers are therefore significant. The academy needs to engage more fully across disciplines that reflect the siting of research - from the 'home' to the 'holiday' and beyond. In so doing, it needs to recognise the spatiality associated with multiple consumption settings and the need to understand how practices are mapped onto these sites. Similarly, the policy community also needs to recognise two uncomfortable realities, namely that knowledge, understanding and appreciation of climate change is still variable to say the least; and perhaps some of the greatest changes needed in tackling climate change are those which are closely related to practices that are performed in highly valued sites of consumption and will therefore be difficult to change. 


\section{References}

Agyeman, J and Angus, B, 2003, “The Role of Civic Environmentalism in the Pursuit of Sustainable Communities" Journal of Environmental Planning and Management $46345-363$

Ajzen, I, 1991, "The Theory of Planned Behavior" Organizational Behavior and Human Decision Processes 50 179-211

Anable J, 2005, “Complacent Car Addicts' or 'Aspiring Environmentalists'? Identifying travel behaviour segments using attitude theory" Transport Policy 12 6578

Barr, S, 2008 Environment and Society: sustainability, policy and the citizen (Ashgate, Aldershot).

Barr S, Gilg A W, and Ford N J, 2001, A conceptual framework for understanding and analysing attitudes towards household waste management Environment and Planning A 33 2025-2048

Barr S, Gilg A W, and Ford N. J, 2005 "The Household Energy Gap: the divide between habitual and purchase-related conservation behaviours" Energy Policy $\mathbf{3 3}$ $1425-1444$

Barr S, and Gilg A W, 2006 "Sustainable Lifestyles: framing environmental action in and around the home" Geoforum 37 906-920

Bechtel R, Churchman A and Ts'erts'man A, (Eds) (2002, Handbook of Environmental Psychology (Wiley, London).

Becken S, 2007, “Tourists' Perception of International Air Travel's Impact on the Global Climate and Potential Climate Change Policies" Journal of Sustainable Tourism 15 351-368 
Becken S and Hay J E, 2007, Tourism and Climate Change (Channel View, Clevedon)

Bulkeley H and Gregson N, 2009, "Crossing the threshold: municipal waste policy and household waste generation”. Environment and Planning A 41 929-945

Burgess J, Harrison C M and Filius P, 1998, "Environmental communication and the cultural politics of environmental citizenship" Environment and Planning A 30 14451460

Chapman L, 2007, "Tourism and climate change: a review" Journal of Transport Geography 15 354-367

Collins A J, 2004, "Can we learn to live differently? Lessons from Going for Green: a case study of Merthyr Tydfil (South Wales)" International Journal of Consumer Studies 28 202-211

Currie R R, 1997, “A pleasure-tourism behaviors framework” Annals of Tourism Research 24 884-897

Dallen J, 2007, Sustainable transport, market segmentation and tourism: the Looe Valley branch line railway, Cornwall, UK” Journal of Sustainable Tourism 15 180199

Darnton A Sharp V, 2006, Segmenting for Sustainability, Reports 1 and 2 (Produced for the Social Marketing Practice, Didcot).

Department of the Environment, 1994 UK Sustainable Development Strategy (HMSO, London).

Department of the Environment, Food and Rural Affairs (DEFRA), 2008 Framework for Environmental Behaviours (DEFRA, London)

Department of the Environment, Food and Rural Affairs (DEFRA), 2005 Securing the Future (DEFRA, London) 
Department of the Environment, Transport and the Regions (DETR), 1999 A better quality of life: A strategy for Sustainable Development for the UK (DETR, London)

De Groot J I M and Steg L, 2008, "Value Orientations to Explain Beliefs Related to Environmental Significant Behavior: How to Measure Egoistic, Altruistic, and Biospheric Value Orientations" Environment and Behavior 40 330-354

Derksen L and Gartell J, 1993, “The social context of recycling" American Sociological Review $\mathbf{5 8} 434-442$

De Young R, 2000, "Expanding and evaluating motives for environmentally responsible behavior" Journal of Social Issues $\mathbf{5 6} 509-526$

Dickinson J E and Dickinson J A, 2006, “Local Transport and Social Representations: Challenging the Assumptions for Sustainable Tourism" Journal of Sustainable Tourism 14 192-208

Eden S, 1993, "Individual environmental responsibility and its role in public environmentalism” Environment and Planning A 25 1743-1758

Eden S, 1996, "Public participation in environmental policy: considering scientific, counter-scientific and non-scientific contributions" Public Understanding of Science $\mathbf{5}$ $183-204$

Fishbein M and Ajzen I, 1975 Belief, attitude, intention and behavior: An introduction to theory and research (Addison-Wesley, Reading, MA) French J, Blair-Stevens C, McVey D and Merritt R, 2009, Social Marketing and Public Health: Theory and Practice (Oxford University Press, Oxford).

Giddens A, 2009, The Politics of Climate Change (Polity Press, Cambridge)

Gössling S and Hall C M, Eds, Tourism and Global Environmental Change: ecological, social, economic and political interrelationships (Routledge, London) 
Gössling S and Peeters P, 2007, “'It Does Not Harm the Environment!' An Analysis of Industry Discourses on Tourism, Air Travel and the Environment" Journal of Sustainable Tourism 15 402-417

Gössling S, Bredberg M, Randow A, Svensson P and Swedlin E, 2006, "Tourist perceptions of climate change: A study of international tourists in Zanzibar" Current Issues in Tourism 9 419-435

Gottlieb A, 1982, “Americans' Vacations” Annals of Tourism Research 9 165-187

Graham B and Shaw J, 2008, "Low-cost airlines in Europe: Reconciling liberalization and sustainability" Geoforum 39 1439-1451

Gregson N, Metcalfe A and Crewe L, 2007, "Identity, mobility and the throwaway society" Environment and Planning D: Society and Space 25 682-700

Guagnano G A, Stern P C and Dietz T, 1995, "Influences on attitude-behavior relationships: a natural experiment with curbside recycling" Environment and Behavior 27 699-718

Hall C M, 2005, Tourism: re-thinking the social science of mobility (Pearson, Harlow) Heffernan O, 2010, “ 'Climategate' scientist speaks out” Nature News February 2010, http://www.nature.com/climate/2010/1003/full/news.2010.71.html.

Hinchliffe S, 1996, "Helping the earth begins at home: social constructions of socioenvironmental responsibility" Global Environmental Change: Human and Policy Dimensions 6 53-62

Hobson K, 2002, "Competing discourses of sustainable consumption: does the “rationalisation of lifestyles" make sense?" Environmental Politics 11 95-120 Hunter C and Shaw J, 2007, "The ecological footprint as a key indicator of sustainable tourism" Tourism Management 28 46-57 
Jackson T, 2005 Motivating Sustainable Consumption: a review of evidence on consumer behaviour and behavioural change (Sustainable Development Research Network, London)

Krippendorf J, 1987 The Holiday Makers: Understanding the Impact of Leisure and Travel (Butterworth-Heinemann, Oxford)

Lorenzoni I, Nicholson-Cole S and Whitmarsh L, 2007 "Barriers perceived to engaging with climate change among the UK and their policy implications" Global Environmental Change 17 445-459.

McKenzie-Mohr D, 2000, "New Ways to Promote Proenvironmental Behavior: Promoting Sustainable Behavior: An Introduction to Community-Based Social Marketing” Journal of Social Issues 56 543-554

Mowforth M and Munt I, 2003 Tourism and Sustainability (Routledge, London)

Owens S, 2000, "Engaging the public: information and deliberation in environmental policy" Environment and Planning A 32 1141-1148

Peattie K and Crane A, 2005, "Green marketing: legend, myth, farce or prophesy?" Qualitative Market Research 8 357-370

Peattie K and Peattie S, 2009 "Social marketing: a pathway to consumption reduction?” Journal of Business Research 62 260-268

Ryley T and Davison L, 2008 "UK air travel preferences: Evidence from an East Midlands household survey" Journal of Air Transport Management 14 43-46

Schultz P W, Oskamp S and Mainieri T, 1995, "Who recycles and when? A review of personal and situational factors" Journal of Environmental Psychology 15 105-121.

Schwartz S H, 1977, "Normative influences on Altruism", in Advances in experimental social psychology: volume 10 Ed L Berkowitz (Academic Press, New York) pp 221-279. 
Scott D, Peeters P and Gössling S, 2010 "Can tourism deliver its "aspirational" greenhouse gas emission reduction targets?" Journal of Sustainable Tourism 18, 393408

Seyfang G, 2005, "Shopping for sustainability: Can sustainable consumption promote ecological citizenship?” Environmental Politics 14 290-306

Sharpley R, 2009 Tourism Development and the Environment: Beyond Sustainability (Earthscan, London)

Sharpley R, 2006 Travel and Tourism (Sage, London)

Shaw G and Williams A M, 2004, Tourism and Tourism Spaces (Sage, London)

Shove E, 2003 Comfort, Cleanliness and Convenience: the social organization of normality (Berg, Oxford).

Shove E and Warde A, 2002, "Inconspicuous Consumption: the sociology of consumption, lifestyles and the environment", in Sociology and the Environment Eds R E Dunlap, F H Buttel and P Dickins (Rowman and Littlefield, Lanham, Maryland) pp 230-251

Spaargaren G and Mol A P J, 2008, "Greening global consumption: Redefining politics and authority" Global Environmental Change 18 350-359

Stern P C, Dietz, T and Guagnano G. A, 1995, "The new ecological paradigm" Environment and Behavior 27 723-743

Tudor T L, Barr S, and Gilg A W, 2008, “A Novel Conceptual Framework for Examining Environmental Behavior in Large Organizations: A Case Study of the Cornwall National Health Service (NHS) in the United Kingdom" Environment and Behavior 40 426-450

Urry J, 2002, The Tourist Gaze (Sage, London)

Urry J, 2007, Mobilities (Polity Press, Cambridge) 
Verbeek D and Mommass H, 2008, “Transitions to Sustainable Tourism Mobility: The Social Practices Approach” Journal of Sustainable Tourism 16 629-644

Wheeler D, Shaw G and Barr S, 2004 Statistical Techniques in Geographical Analysis (Fulton, London). Third edition.

\section{Acknowledgment}

The authors would like to thank the British Academy for the funding to support the research reported in this paper. The authors are also grateful for the constructive comments of three anonymous referees during the review of the manuscript. 
Table 1 Properties of the three behavioural cluster

\begin{tabular}{|c|c|c|c|}
\hline Characteristics & Cluster 1 & Cluster 2 & Cluster 3 \\
\hline $\mathrm{n}$ in cluster* & 52 & 105 & 44 \\
\hline Cluster profile & $\begin{array}{l}\text { Tended to be older, } \\
\text { with a high proportion } \\
\text { of retired }\end{array}$ & $\begin{array}{l}\text { Mostly young and } \\
\text { employed FT }\end{array}$ & $\begin{array}{l}\text { Young / middle aged, } \\
\text { working FT }\end{array}$ \\
\hline $\begin{array}{l}\text { Home-based } \\
\text { environmental } \\
\text { actions of the cluster }\end{array}$ & $\begin{array}{l}\text { Undertook the whole } \\
\text { range of environmental } \\
\text { actions with the greatest } \\
\text { frequency }\end{array}$ & $\begin{array}{l}\text { Tended to be conscious } \\
\text { consumers, buying } \\
\text { organic food, } \\
\text { composting their waste } \\
\text { and buying } \\
\text { environmentally } \\
\text { friendly products. } \\
\text { Tended to recycle, save } \\
\text { energy and water less } \\
\text { often than other clusters }\end{array}$ & $\begin{array}{l}\text { Tended to save water and } \\
\text { energy in the home and to } \\
\text { purchase devices that } \\
\text { helped them do this. } \\
\text { Tended to make } \\
\text { environmentally } \\
\text { conscious purchases, } \\
\text { compost their waste and } \\
\text { buy organic food less } \\
\text { frequently. }\end{array}$ \\
\hline $\begin{array}{l}\text { Environmental } \\
\text { actions on holiday of } \\
\text { the cluster }\end{array}$ & $\begin{array}{l}\text { Most committed to } \\
\text { environmental actions } \\
\text { on holiday }\end{array}$ & $\begin{array}{l}\text { Least committed to } \\
\text { environmental actions } \\
\text { on holiday }\end{array}$ & $\begin{array}{l}\text { Committed to saving } \\
\text { energy and water on } \\
\text { holiday }\end{array}$ \\
\hline $\begin{array}{l}\text { Holiday taking in the } \\
\text { cluster }\end{array}$ & $\begin{array}{l}\text { UK } 28 \% \\
\text { Europe } 33 \% \\
\text { Int. } 39 \%\end{array}$ & $\begin{array}{l}\text { UK } 34 \% \\
\text { Europe } 50 \% \\
\text { Int. } 16 \%\end{array}$ & $\begin{array}{l}\text { UK } 29 \% \\
\text { Europe } 50 \% \\
\text { Int. } 21 \%\end{array}$ \\
\hline $\begin{array}{l}\text { Average nights away } \\
\text { on main holiday for } \\
\text { cluster }\end{array}$ & 12 & 9 & 12 \\
\hline $\begin{array}{l}\text { Mean flights in last } \\
12 \text { months for cluster }\end{array}$ & 2.6 & 2.3 & 2.3 \\
\hline $\begin{array}{l}\text { Attitudes to taxes on } \\
\text { air travel for cluster }\end{array}$ & $50 \%$ in favour of tax & $38 \%$ in favour of tax & $36 \%$ in favour of tax \\
\hline $\begin{array}{l}\text { Heard of carbon off- } \\
\text { setting (for cluster) }\end{array}$ & $73 \%$ & $52 \%$ & $39 \%$ \\
\hline $\begin{array}{l}\text { Used carbon off- } \\
\text { setting (for cluster) }\end{array}$ & $36 \%$ & $11 \%$ & $0 \%$ \\
\hline $\begin{array}{l}\text { Interviewee cluster } \\
\text { membership for } \\
\text { comparison }\end{array}$ & $\begin{array}{l}\text { Pat } \\
\text { Anna } \\
\text { Jean } \\
\text { Janet } \\
\text { Jane }\end{array}$ & $\begin{array}{l}\text { Donna } \\
\text { Martin } \\
\text { Gill } \\
\text { Tony }\end{array}$ & $\begin{array}{l}\text { Dan } \\
\text { Gemma } \\
\text { John }\end{array}$ \\
\hline
\end{tabular}

* n 201 as one case contained too much missing data 
